\title{
Information and output in agricultural markets: the role of market transparency
}

\author{
Christian Ahlers ${ }^{1}$, Udo Broll ${ }^{*}$ and Bernhard Eckwert ${ }^{3}$
}

\author{
*Correspondence: \\ udo.broll@tu-dresden.de \\ ${ }^{2}$ Department of Business and \\ Economics, School of International \\ Studies, Technische Universität \\ Dresden, Helmholtzstr. 10, 01069 \\ Dresden, Germany \\ Full list of author information is \\ available at the end of the article
}

\begin{abstract}
This study is concerned with the impact of changes in market transparency on agricultural production levels. Market transparency is of central importance in the agri-food system as it affects the degree of uncertainty farmers face when taking economic decisions. In our study, we endogenize uncertainty by establishing a link between market transparency and the terms of contracting on the futures market. We find that a higher degree of market transparency leads to higher expected profits but does not increase agricultural production levels per se. However, when farmers have no access to futures markets, transparency does increase ex ante expected uility and output.
\end{abstract}

Keywords: Market transparency; Agriculture; Price risk; Information

\section{Background}

Markets for important food staples as grains and vegetable oils have seen a great deal of turmoil over the past decade. Particularly, uncertainty associated with price volatility negatively affects investment and production decisions by risk-averse farmers. An intuitive illustration is given by Figure 1 that displays the FAO real monthly food as well as the respective cereals price index. The data shows that global food markets exhibited serious patterns of uncertainty over the past decade.

However, the role of technology adoption and adjustment of supply is of central importance with respect to securing adequate levels of agricultural production and achieving global food security. Consequently, recent studies stressed the role of market transparency and information flows for improving production decisions in agricultural markets (see UNCTAD 2011). Thus, market transparency can be understood in terms of parameters that, at least partially, are under control of public and private agencies. Governmental and non-governmental organizations then may enhance transparency by providing a greater deal and more reliable information on important determinants of price movements, such as indicators of climate change, international market conditions, government price stabilization schemes, weather forecasts, disaster relief programs, stricter food safety standards, insurance and alternatives (UNCTAD 2011).

Against this background, the present study is concerned with the impact of changes in markets transparency on agricultural production levels. In particular, we study how the

(c2013 Ahlers et al.; licensee Springer. This is an Open Access article distributed under the terms of the Creative Commons

Attribution License (http://creativecommons.org/licenses/by/2.0), which permits unrestricted use, distribution, and reproduction in any medium, provided the original work is properly cited. 


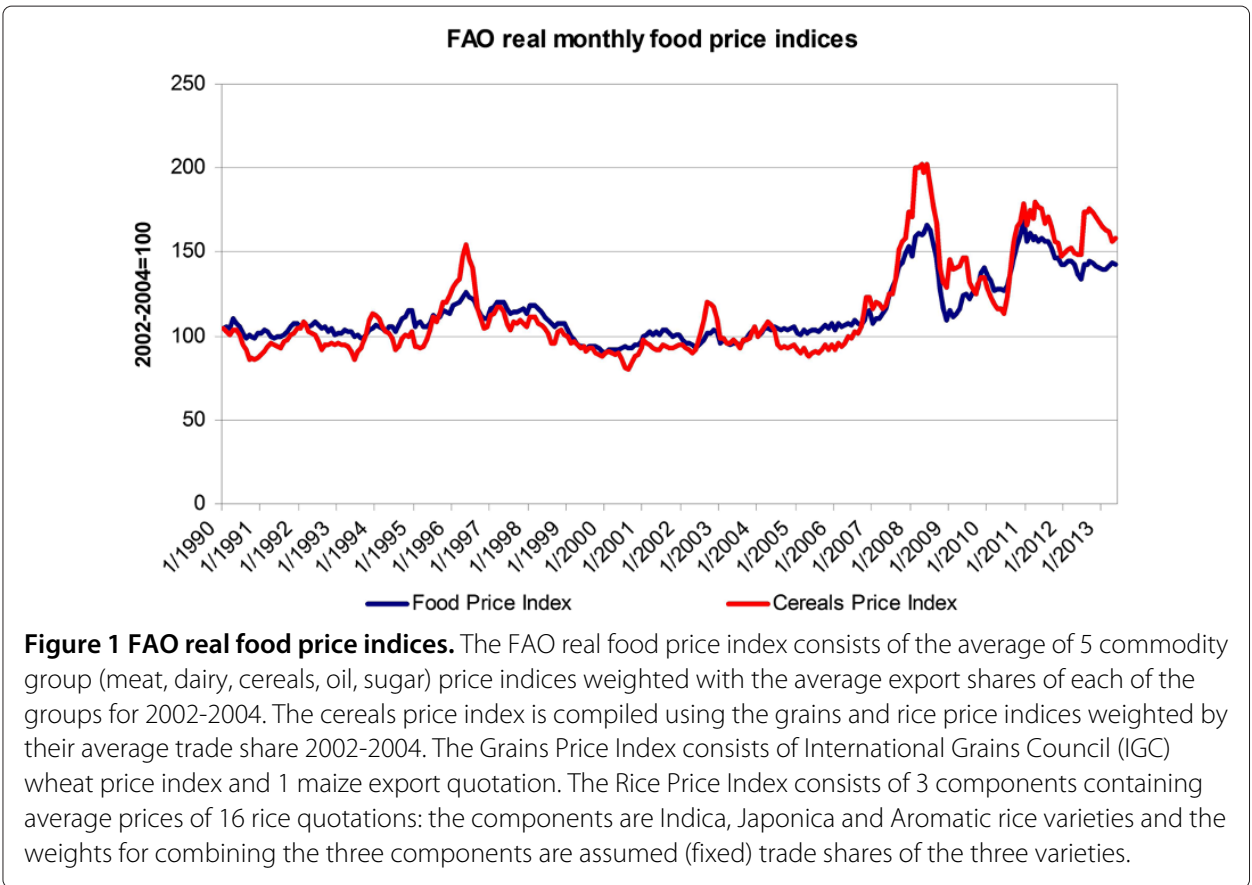

ex ante expected volume of agricultural production responds to additional information when information also affects the futures market for agricultural commodities. Earlier studies addressing this issue have modeled market transparency solely by means of exogenous changes in the distributional parameters of the market price. In such a framework, the futures market is completely separated from the underlying transparency concept (see Newbery and Stiglitz 1981, Kawai and Zilcha 1986, Frechette 2000, Moschini and Hennessy 2001, Allen and Lueck 2003 as well as Hudson 2007).

In our view, this approach misses out an important link that exists between market transparency and risk-sharing opportunities on futures markets. In our model, we endogenize uncertainty through an information system provided by governmental and nongovernmental organizations or related agencies that explicitly links market transparency to the terms of contracting on the futures market.

The notion of market transparency underlying this approach is adopted from the work of Eckwert and Zilcha (2001, 2003). Along the seminal contributions of Blackwell (1953) and Hirshleifer (1971), market transparency is linked to the informativeness of an observable signal which is (imperfectly) correlated with the future spot price. The uncertainty the farmer is exposed to then depends on the observed signal as well as on the information system within which the signal can be interpreted. We find that a higher degree of market transparency leads to higher expected profits but does not increase agricultural production levels per se. However, when we vary the prevailing risk-sharing regime such that farmers have no access to futures markets, transparency does increase ex ante expected utility and output.

In particular, we consider a model where a farmer faces risky revenues due to a random product price. The distribution of the price is given and there exists a futures market (see, for example, Broll et al. 2013). The terms at which the farmer can hedge the revenue risk through trade in futures contracts negatively depends on the degree of 
market transparency. Higher market transparency then affects the farmer's production decision in two opposing ways. Firstly, price uncertainty declines and ex ante expected utility increases, resulting in higher production levels. Secondly, additional information on future market conditions may interfere with the operation of risk-sharing markets and thereby decrease ex ante expected utility and production levels.

The paper is organized as follows. In section 'Methods', we introduce the model and our concepts of information and market transparency. Our main results are derived in section 'Results and discussion'. Section 'Conclusions' concludes.

\section{Methods}

The farmer produces in period 0 and sells her products in period 1 for a random price. Production costs, $c(q)$, are a strictly increasing and convex function of the volume of production $q$. The firm's random revenues, as of date 1 , are $\tilde{p} q$, where $\tilde{p}$ is the one period ahead spot market price. The tilde refers to the random nature of the spot price which assumes values in $\Omega:=[\underline{p}, \bar{p}]$, where $0<\underline{p}<\bar{p}<\infty$.

Prior to choosing a production level, the farmer observes a signal $s$ from a governmental or non-governmental organization and/or a related agency. This signal is the realization of a random variable $\tilde{s}$ which is correlated with $\tilde{p}$. The signal contains public information about the unknown future market price $p$. Thus, at the time when input and production decision are made, the relevant price expectation is the updated in a Bayesian way. Figure 2 depicts how the sequence of events unfolds in the model.

Futures markets for agricultural commodities open at date 0 after the signal has been observed. Let $h$ be the future commitment of the farmer, i.e., $h$ denotes the number of futures contracts sold by the farmer. To focus on the farmer's hedging motive as opposed to a speculative motive, we assume that the commodity derivative is unbiased. Therefore, the forward rate $f_{0}(s)$ is equal to the conditional mean of a contract's payoff,

$$
f_{0}(s)=\mathrm{E}[\tilde{p} \mid s] .
$$

Both, the payoff and the purchase price of the contract fall due in period 1.

\section{The farmer's decision problem}

The risk-averse farmer is maximizing expected utility, defined over random profits, $\tilde{\Pi}$, i.e.

$$
\tilde{\Pi}=\tilde{p} q-c(q)-\left(\tilde{p}-f_{0}(s)\right) h .
$$

The decision making problem can be written as

$$
\max _{q, h} \mathrm{E}[U(\tilde{\Pi}) \mid s],
$$

$$
\begin{aligned}
& \text { The public signal is observed. } \\
& \begin{array}{ll}
\text { The farmer makes her production } \\
\text { and hedging decisions. }
\end{array} \\
& \text { The farmer sells her output and } \\
& \text { settles her futures position. }
\end{aligned}
$$

Figure 2 Sequence of events. 
where $U$ is a strictly increasing, strictly concave and twice continuously differentiable utility function. The necessary first-order conditions, which are also sufficient, are

$$
\begin{aligned}
& \mathrm{E}\left[U^{\prime}(\tilde{\Pi})\left(\tilde{p}-c^{\prime}(q)\right) \mid s\right]=0, \\
& \mathrm{E}\left[U^{\prime}(\tilde{\Pi})\left(f_{0}(s)-\tilde{p}\right) \mid s\right]=0,
\end{aligned}
$$

where $U^{\prime}$ and $c^{\prime}$ are denoting marginal utility and marginal cost of production. From (4), (5) and the unbiasedness assumption, we obtain the optimal levels of production and hedging:

$$
c^{\prime}(q(s))=f_{0}(s) \text { and } h=q(s) .
$$

For our model, equation (6) establishes the validity of the separation theorem and the full-hedging hypothesis. Thus, in the presence of risk-sharing markets, entrepreneurial decisions are independent of attitudes towards risk and, moreover, all risks will be fully hedged if the futures market is unbiased (see, for example, Wong 2007). Next we define our notion of market transparency. Following Eckwert and Zilcha (2001, 2003), transparency will be linked to the informational content of the signal $s$ under different information systems and risk-sharing regimes.

\section{Information systems and market transparency}

We identify the transparency of a market with the informativeness of the signal $s \in S$, which is provided by a governmental or non-governmental organization or a related agency. The informativeness of a given signal then depends on the information system within which the signal can be interpreted. An information system, denoted by $g$, specifies for each state of nature, $p$, a conditional probability function over the set of signals: $g(s \mid p)$. The positive real number $g(s \mid p)$ defines the conditional probability (density) that the signal $s$ will be observed if the true (yet unknown) state of nature is $p_{1}$. Using Bayes' rule, the farmer revises her expectations and maximizes utility on the basis of the updated beliefs.

The density for the prior distribution over $S$ is given by

$$
v(s)=\int_{S} g(s \mid p) \pi(p) \mathrm{d} p \text { for all } s,
$$

where $\pi$ denotes the Lebesgue density function for the prior distribution over $S$. The density function for the updated posterior distribution over $S$ is

$$
v(p \mid s)=g(s \mid p) \pi(p) / v(s) .
$$

Blackwell (1953) suggested a criterion that ranks different information systems according to their informational content. Suppose $g^{1}$ and $g^{2}$ are two information systems with associated density functions $v^{1}(\cdot)$ and $v^{2}(\cdot)$. The following criterion induces an ordering on the set of information systems.

Information systems. The information system $g^{1}$ is said to be more informative than $g^{2}$ if there exists an integrable function $\lambda$ such that

$$
\int_{S} \lambda\left(s^{\prime}, s\right) d s^{\prime}=1
$$

holds for all $s$, and

$$
g^{2}\left(s^{\prime} \mid p\right)=\int_{S} g^{1}(s \mid p) \lambda\left(s^{\prime}, s\right) d s
$$

holds for all $p \in S$. 
According to this criterion $g^{1} \succ_{\text {inf }} g^{2}$, holds if $g^{2}$ can be obtained from $g^{1}$ through a process of randomization. The probability density $\lambda\left(s^{\prime}, s\right)$ in equation (10) transforms a signal $s$ into a new signal $s^{\prime}$. If the $s^{\prime}$-values are generated in this way, the information system $g^{2}$ can be interpreted as being obtained from the information system $g^{1}$ by adding random noise. Therefore, the signals under information system $g^{2}$ convey no information about the value of $\tilde{p}$ that is not already conveyed by the signals under information system $g^{1}$. As a consequence, the a priori expected posterior price uncertainty under $g^{1}$ will be lower than under $g^{2}$.

As noted before, our notion of market transparency is based on the informational content of the signal $s$. We characterize a market as more transparent if the signal conveys more precise information about the future market price.

Market transparency. Agri-food markets are said to be more transparent under $g^{1}$ than under $g^{2}$ if $g^{1} \succ_{\text {inf }} g^{2}$.

The following lemma contains a property of information systems that turns out to be a very convenient tool for economic analysis. The lemma formulates a transparency criterion that is equivalent to the condition stated above.

Lemma 1. The agri-food market is more transparent under $g^{1}$ than under $g^{2}$ if and only if

$$
\int_{S} F\left(v^{1}(\cdot \mid s)\right) v^{1}(s) d s \geq \int_{S} F\left(v^{2}(\cdot \mid s)\right) v^{2}(s) d s
$$

holds for every convex function $F(\cdot)$ on the set of density functions over $\Omega$.

A proof of Lemma 1 can be found in Kihlstrom (1984). Note that $v^{1}(\cdot \mid s)$ and $v^{2}(\cdot \mid s)$ are the posterior beliefs under the two information systems. Thus, Lemma 1 implies that higher transparency (weakly) raises the expectation of any convex function of posterior beliefs. In other words, additional information is equivalent to introducing a mean preserving spread in the probability of success. If the maximum expected utility is a convex function of the probability of success, information raises the ex ante expected utility of any risk-averse farmer.

\section{Results and discussion}

We now turn to the question how the ex ante expected volume of agricultural output is affected when the market becomes more transparent, i.e. when additional public information about future market conditions becomes available. We consider two cases. First, we assume that the farmer has full access to futures markets to hedge her revenue risk. In a second step, we consider a world where the farmer has no access to futures markets or other risk-sharing opportunities.

\section{Impact of market transparency in the presence of futures market}

The production, $q$, is contingent on the signal $s$. We define the volume of production, $Q$, as the average agricultural output before the signal has been observed,

$$
Q=E_{s}[q(s)]=\int_{S} q(s) v(s) \mathrm{d} s
$$

Now we characterize the impact of higher market transparency on the volume of production in terms of the curvature of the marginal cost function. 
Proposition 1. Higher transparency in the agricultural market leads to a higher (lower) expected level of supply if, and only if, the marginal cost function, $c^{\prime}(q)$, is strictly concave (convex).

Proof of Proposition 1. It is evident from equation (1) that $f_{0}$ is a linear function of the posterior probability density function, $v(p \mid s)$. Lemma 1 and equation (11) imply that the average level of supply increases (decreases) with higher transparency in the agricultural market if, and only if, $q\left(f_{0}\right)$ is strictly convex (concave) in $f_{0}$. From equation (6) we obtain

$$
q^{\prime \prime}\left(f_{0}\right)=-\frac{c^{\prime \prime \prime}\left[q\left(f_{0}\right)\right]}{c^{\prime \prime}\left[q\left(f_{0}\right)\right]^{2}}
$$

The desired result follows from equation (12).

As just seen, the impact of higher transparency on agricultural production depends only on the curvature of the marginal cost function. Concavity of the marginal cost function is a pattern sometimes seen in agriculture where the presence of fixed input factors (e.g. land and building of fixed size) constrains production.

By contrast, production processes that exhibit high substitutability among input factors may give rise to convex marginal cost functions. If the cost function is quadratic, i.e. the marginal cost function is linear, production will not be affected by changes in market transparency.

The result in Proposition 1 differs from the role attributed to market transparency in earlier studies which have modeled changes in transparency simply by means of an exogenous change in the distributional parameters of the market price. Our approach implies that market transparency affects the terms of contracting on the futures market and, hence, the farmer's production decision and output. The endogenous terms of futures contracting, therefore, constitutes an important link through which market transparency may affect the volume of supply in agricultural markets.

To illustrate our result and the impact of market transparency on the expected level of agricultural supply, we now consider an example with binary information structure. Under information system $g^{1}$, the signal provides full information about the future market price. Under information system $g^{2}$ the signal is completely uninformative.

\section{Example}

The farmer's cost function takes the form $c(q)=(1 / a) q^{a}, a>1$. The signal space contains two signals, $s_{1}$ and $s_{2}$. The market price takes the values $p_{1}$ and $p_{2}, p_{1}<p_{2}$ with prior probabilities equal to $1 / 2$. The information system is given by the conditional probabilities $g\left(s_{1} \mid p_{1}\right)=g\left(s_{2} \mid p_{2}\right)=\beta$, and $g\left(s_{1} \mid p_{2}\right)=g\left(s_{2} \mid p_{1}\right)=1-\beta, \beta \in[1 / 2,1]$. The parameter $\beta$ measures the transparency of the agricultural market: for $\beta=1$ the information system is fully informative indicating a transparent market; for $\beta=1 / 2$ the information system is fully uninformative indicating an intransparent agricultural market.

The prior signal probabilities are

$$
n\left(s_{1}\right)=g\left(s_{1} \mid p_{1}\right) f\left(p_{1}\right)+g\left(s_{1} \mid p_{2}\right) f\left(p_{2}\right)=n\left(s_{2}\right)=1 / 2 .
$$


The posterior state probabilities can be calculated as

$$
v\left(p_{1} \mid s_{1}\right)=v\left(p_{2} \mid s_{2}\right)=\beta \quad \text { and } \quad v\left(p_{2} \mid s_{1}\right)=v\left(p_{1} \mid s_{2}\right)=1-\beta .
$$

From (13) and (14) we get

$$
\begin{aligned}
& f_{0}\left(s_{1}\right)=p_{1}+\left(p_{2}-p_{1}\right)(1-\beta), \\
& f_{0}\left(s_{2}\right)=p_{1}+\left(p_{2}-p_{1}\right) \beta .
\end{aligned}
$$

The separation theorem (see equation (6)) implies $q=\left(f_{0}\right)^{1 /(a-1)}$. Therefore, ex ante expected output, $Q$, reads

$$
Q=\frac{1}{2}\left\{\left[p_{1}+\left(p_{2}-p_{1}\right)(1-\beta)\right]^{1 /(a-1)}+\left[p_{1}+\left(p_{2}-p_{1}\right) \beta\right]^{1 /(a-1)}\right\} .
$$

Now we compare the expected output supply in a transparent market, $Q_{t}$, with the expected output volume in an intransparent agricultural market, $Q_{i t}$. Setting $\beta=1$ and $\beta=1 / 2$ we get

$$
\begin{aligned}
& Q_{t}=\frac{1}{2}\left[p_{1}^{1 /(a-1)}+p_{1}^{1 /(a-1)}\right], \\
& Q_{i t}={\frac{\left(p_{1}+p_{2}\right)}{2}}^{1 /(a-1)} .
\end{aligned}
$$

Let us choose $p_{1}=5, p_{2}=15$ and $a=11 / 10$. Then, the ratio $Q_{t} / Q_{i t}$ is much larger than 1 . If $a$ takes values larger than 2 , then ratio $Q_{t} / Q_{i t}$ is smaller than 1 . In that case, higher market transparency reduces the expected volume of agricultural supply. However, the effect tends to be small.

Before we vary the prevailing risk-sharing regime, we now turn to the impact of changes in market transparency on the farmer's expected profits.

Proposition 2. Higher transparency in the agricultural market always leads to an increase in the farmer's expected profits. Ex ante expected profits

$$
\mathrm{E}(\tilde{\Pi})=\int_{S} \Pi(s) v(s) d s
$$

are higher under $g^{1}$ than under $g^{2}$.

Proof of Proposition 2. Proceeding along the same lines as in the proof of Proposition 1 we need to show that

$$
\Pi\left(f_{0}\right)=f_{0} q\left(f_{0}\right)-c\left(q\left(f_{0}\right)\right)
$$

is a convex function of $f_{0}(s)$. In the optimum, differentiating with respect to $f_{0}$ yields

$$
\Pi^{\prime}\left(f_{0}\right)=q\left(f_{0}\right)>0 \text { and } \Pi^{\prime \prime}\left(f_{0}\right)=q^{\prime}\left(f_{0}\right)>0 .
$$

An increase in $f_{0}$ has a first-order effect on the farmer's maximum profit through the revenues $f_{0} q\left(f_{0}\right)$. Since the farmer sells more when $f_{0}$ increases, this first-order effect on $\Pi\left(f_{0}\right)$ is stronger for larger values of $f_{0}$ and weaker for lower values. As a result, the farmer's profit function is convex in the forward rate. A more transparent agricultural market makes $f_{0}$ more sensitive to changes in the public signal, thereby leading to higher expected profits. 
According to Proposition 2, higher market transparency leads to higher expected profits regardless of attitudes towards risk and of technological parameters as long as the cost function is convex. This result does not imply, however, that the farmer will be better off in terms of ex ante expected utility. When the signal affects an insurable risk, like in our model, the value of additional information depends on two opposing effects.

Firstly, when the farmer receives more reliable information she is able to improve her decisions, thereby increasing ex ante expected utility (Blackwell effect). Secondly, as was pointed out by Hirshleifer (1971), additonal information may interfere with the operation of risk-sharing markets thereby destroying some risk-sharing opportunities. Since the farmer is risk-averse, ex ante expected utility declines. Due to these opposing effects, the overall impact of higher market transparency on the farmer's ex ante expected utility is ambiguous.

Impact of market transparency in the absence of futures market

To further illustrate the interaction between the Blackwell and the Hirshleifer effect, we now consider the case when the farmer has no access to futures markets or other risksharing opportunities. The above results suggest that the (negative) Hirshleifer effect vanishes and the ex ante expected utility depends on the (positive) Blackwell effect only.

Proposition 3. If agricultural commodities cannot be traded on a futures market at date 0 , ex ante expected utility is higher under information system $g^{1}$ than under $g^{2}$.

Proof of Proposition 3. In the absence of a futures market, the first-order condition for a farmer's decision problem reads

$$
\mathrm{E}\left[U^{\prime}(\tilde{\Pi})\left(\tilde{p}-c^{\prime}(q)\right) \mid s\right]=0 .
$$

Denote the unique solution to (23) by $q(s)$ and define

$$
U(q(s), p)=U[p q(s)-c(q(s))] .
$$

The value function is

$$
V(v(\cdot) \mid s)=\int_{S} U(q(s), p) v(p \mid s) d p .
$$

To proof our proposition, we have to show that the value function is convex in the posterior belief $v(\cdot \mid s)$. Assume $v(\cdot \mid s)=\beta v^{1}(\cdot \mid s)+(1-\beta) v^{2}(\cdot \mid s), \beta \in[0,1]$. Denote by $q^{1}(s)$ and $q^{2}(s)$ the optimal agricultural supply under the posterior beliefs $v^{1}(\cdot \mid s)$ and $v^{2}(\cdot \mid s)$, respectively. We obtain

$$
\begin{aligned}
V(v(p \mid s)) & =\int_{S} U(q(s), p)\left[\beta \nu^{1}(p \mid s)+(1-\beta) v^{2}(p \mid s)\right] d p \\
& =\beta \int_{S} U(q(s), p) v^{1}(p \mid s) d p+(1-\beta) \int_{S} U(q(s), p) v^{2}(p \mid s) d p \\
& \leq \beta \int_{S} U(q(s), p) \nu^{1}(p \mid s) d p+(1-\beta) \int_{S} U(q(s), p) v^{2}(p \mid s) d p \\
& =\beta V\left(v^{1}(p \mid s)\right)+(1-\beta) V\left(v^{2}(p \mid s)\right) .
\end{aligned}
$$


The inequality holds because $q^{1}(s)$ and $q^{2}(s)$ maximize expected utility if the posterior belief is given by $v^{1}(\cdot \mid s)$ and $v^{2}(\cdot \mid s)$, respectively. We have shown that the value function is convex in the posterior belief. The claim in the proposition then follows from Lemma 1.

Proposition 3 captures the direct welfare effect resulting from market transparency: since, by assumption, agricultural price risk cannot be hedged, the allocation of risk remains unaffected when the agricultural and food market becomes more transparent. All farmers benefit from higher market transparency because their exposure to price risk is lower at the time when they make their production decisions. It can be shown that transparency does increase ex ante expected output when the cost function is convex.

However, things are different when price risk can be hedged. While the direct welfare effect continues to be operative, an indirect welfare effect emerges: higher transparency destroys some risk-sharing opportunities and thereby imposes welfare costs on riskaverse farmers. If farmers are strongly risk-averse, the adverse indirect welfare effect dominates the favorable direct welfare effect and overall welfare decreases with higher market transparency. The normative implications of our economic issue for the agricultural and food sector thus depend on the risk-sharing opportunities available in the agri-food system.

\section{Conclusions}

In this paper, we have studied the impact of changes in market transparency on agricultural production levels. In particular, we have asked how the ex ante expected volume of agricultural production responds to additional information when information also affects the futures market for agricultural commodities. The analysis has produced two main results. Firstly, higher market transparency increases farmers' expected profits as long as the cost function is convex. However, higher market transparency does not increase agricultural production levels per se. If farmers' marginal cost functions are concave (convex), higher market transparency leads to higher (lower) ex ante expected levels of agricultural production.

Secondly, economic interpretation reveals that the value of additional information depends on two opposing effects. When farmer receive more reliable information they are able to improve their decisions, thereby increasing ex ante expected utility. However, additional information may interfere with the operation of risk-sharing markets thereby destroying some risk-sharing opportunities. Since farmers are risk-averse, ex ante expected utility declines. Due to these opposing effects, the overall impact of higher market transparency on farmers' ex ante expected utility remains ambiguous. Accordingly, when we vary the prevailing risk-sharing regime and assume that farmers have no access to futures markets or other risk-sharing opportunities, higher market transparency indeed does increase expected utility and leads to higher agricultural production levels.

Competing interests

The authors declare that they have no competing interests.

Authors' contributions

All authors read and approved the final manuscript. 


\section{Author details}

${ }^{1}$ School of International Studies, Technische Universität Dresden, Dresden, Germany. ${ }^{2}$ Department of Business and Economics, School of International Studies, Technische Universität Dresden, Helmholtzstr. 10, 01069 Dresden, Germany.

${ }^{3}$ Department of Economics, University of Bielefeld, Bielefeld, Germany.

Received: 5 March 2013 Accepted: 28 October 2013

Published: 05 Dec 2013

\section{References}

Allen DW, Lueck D (2003) The nature of the farm: contracts, risk, and organization in agriculture. MIT Press, Cambridge, London

Blackwell D (1953) Equivalent comparison of experiments. Ann Math Stat 24: 265-272

Broll U, Welzel P, Wong KP (2013) Price risk and risk management in agriculture. Contemp Econ 7: 17-20

Eckwert B, Zilcha I (2001) The value of information in production economies. J Econ Theory 100: 172-186

Eckwert B, Zilcha I (2003) Incomplete risk sharing arrangements and the value of information. Econ Theory 21:43-58

Frechette DL (2000) The demand for hedging and the value of hedging opportunities. Am J Agric Econ 82: 897-907

Hirshleifer J (1971) The private and social value of information and the reward to incentive activity. Am Econ

Rev 61: 561-574

Hudson D (2007) Agricultural markets and prices. Blackwell, Malden and Oxford

Kawai M, Zilcha I (1986) International trade with forward futures markets under exchange rate and price uncertainty. J Int Econ 20: 83-98

Kihlstrom RE (1984) A Bayesian exposition of Blackwell's theorem on the comparison of experiments. In: Boyer M, Kihlstrom RE (eds) Bayesian Models of Economic Theory. Elsevier, North-Holland, Amsterdam, pp 13-31

Moschini G, Hennessy DA (2001) Uncertainty, risk aversion, and risk management for agricultural producers. In: Gardner B, Rausser G (eds) Handbook of Agricultural Economics (Vol. 1a). Elsevier, Amsterdam, pp 88-153

Newbery DMG, Stiglitz JE (1981) The theory of commodity price stabilization. Clarendon Press, Oxford

UNCTAD (2011) Price formation in financialized commodity markets: The role of information, New York and Geneva Wong KP (2007) Operational and financial hedging for exporting firms. Int Rev Econ Finance 16: 459-470

10.1186/2193-7532-1-15

Cite this article as: Ahlers et al:: Information and output in agricultural markets: the role of market transparency. Agricultural and Food Economics 2013, 1:15

\section{Submit your manuscript to a SpringerOpen ${ }^{\circ}$ journal and benefit from:}

- Convenient online submission

- Rigorous peer review

- Immediate publication on acceptance

- Open access: articles freely available online

- High visibility within the field

- Retaining the copyright to your article

Submit your next manuscript at $\boldsymbol{\triangleright}$ springeropen.com 